\title{
The many faces of gastrointestinal T-cell lymphoma manifest simultaneously in the same patient
}

A 50-year-old man with a history of AIDS presented with complaints of dyspnea on exertion, anemia, and melena. Seven years prior to the current presentation, he presented with intussusception, underwent right hemicolectomy, and was diagnosed with a cecal mass consistent with T-cell lymphoma. He was noncompliant with his medication regime and was lost to follow-up until the current admission. He underwent esophagogastroduodenoscopy and colonoscopy for further evaluation of iron-deficiency anemia and melena. Upper gastrointestinal endoscopy revealed: (1) multiple concentric rings in the lower esophagus, (2) a small (4-mm) nodule in gastric cardia, and (3) a nodule with central ulceration in the gastric body ( Fig. 1). Colonoscopy showed: (1) a large mass protruding from the small intestine into the ileocolonic anastomosis, (2) ulceration within the blind loop at the anastomosis, and (3) a sessile polyp in the sigmoid colon ( Fig.2). Pathology review of specimens from all of these sites revealed a high-grade peripheral $\mathrm{T}$-cell lymphoma positive for T-cell markers CD4 and patchy for CD3. Immunostaining was negative for CD7 and CD8 ( $\mathbf{F i g . 3}$ ). The patient was started on appropriate highly active antiretroviral therapy (HAART) therapy and chemotherapy.

The gastrointestinal tract is the most commonly involved site for extranodal primary non-Hodgkin lymphomas, accounting for $30 \%-40 \%$ of all cases [1]. Histopathologically, lymphomas with B-cell origins form a major subset (over $90 \%$ ) of all gastrointestinal non-Hodgkin lymphomas compared to T-cell lymphomas and Hodgkin disease, which are observed less frequently [2]. HIV-infected individuals, like our patient, have been known to be at risk for development of a T-cell lymphomas affecting multiple organs [3]. This case illustrates the vast array of endoscopic appearances of gastrointestinal tract involvement of T-cell lymphoma in a single patient at different locations. Esophageal
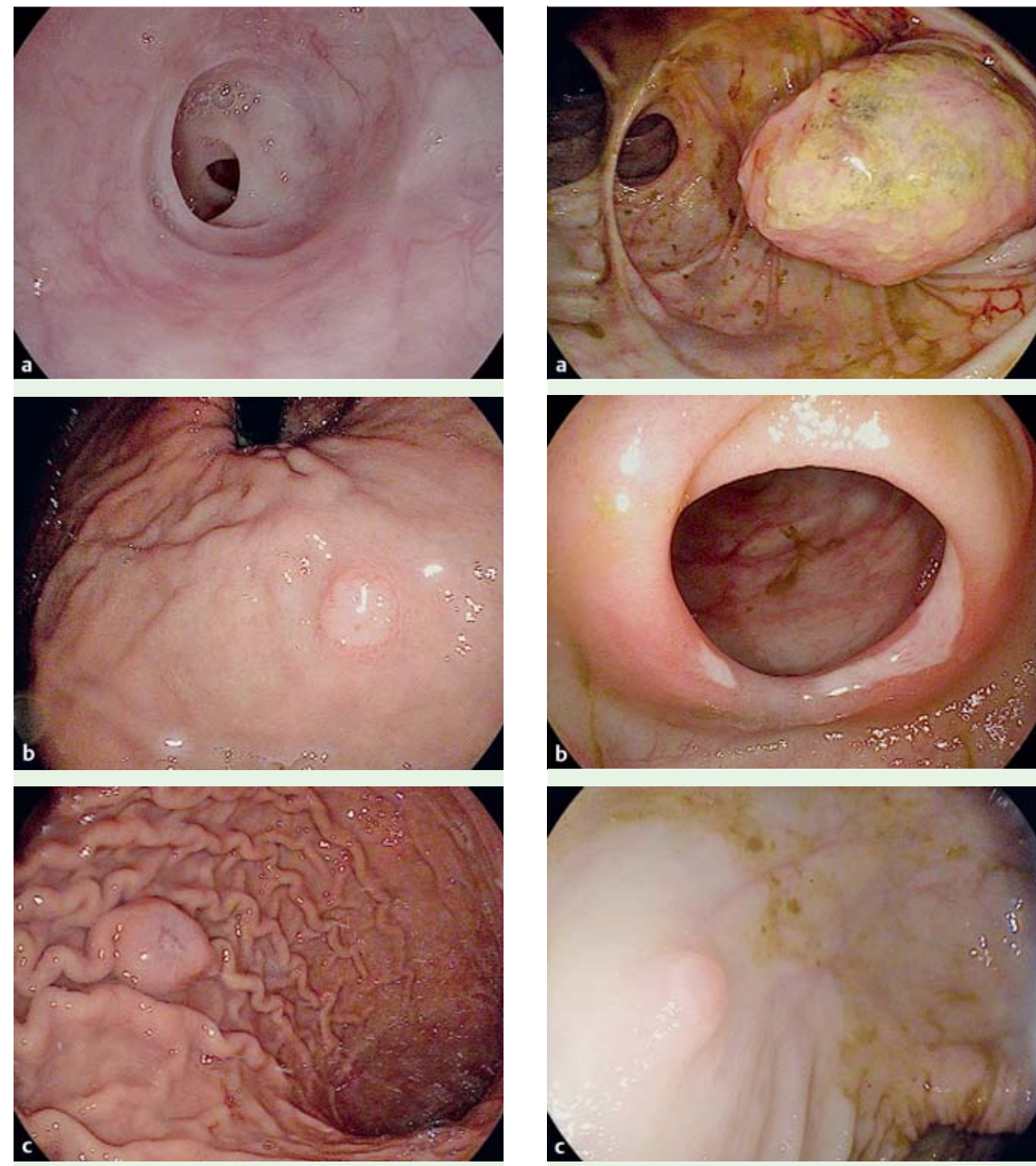

Fig. 1 Esophagogastroduodenoscopy images: a concentric rings in lower esophagus, b nodule at gastric cardia, and $\mathbf{c}$ nodule with central ulceration in gastric body.

involvement in T-cell lymphoma is extremely rare [4], and endoscopic findings of multiple concentric rings in the esophagus due to T-cell lymphoma have to the best of our knowledge never been reported in the literature.

\section{Endoscopy_UCTN_Code_CCL_1AC_2AC}

Competing interests: None

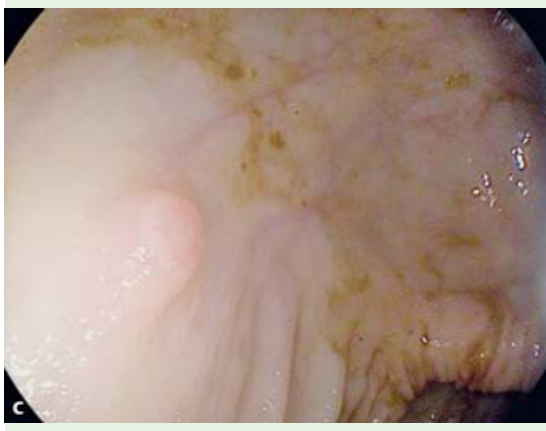

Fig. 2 Colonoscopy images: a protruding mass at ileocolonic anastomosis, b ulceration within blind loop at ileocolonic anastomosis, and $\mathbf{c}$ sessile polyp at sigmoid colon.

\section{N. Thosani ${ }^{1}$, A. Quesada ${ }^{2}$, D. Kulkarni ${ }^{1}$, D. S. Wolf'}

${ }^{1}$ Division of Gastroenterology, Hepatology and Nutrition, The University of Texas Medical School at Houston, Houston, Texas, USA

${ }^{2}$ Department of Pathology, The University of Texas Medical School at Houston, Houston, Texas, USA 


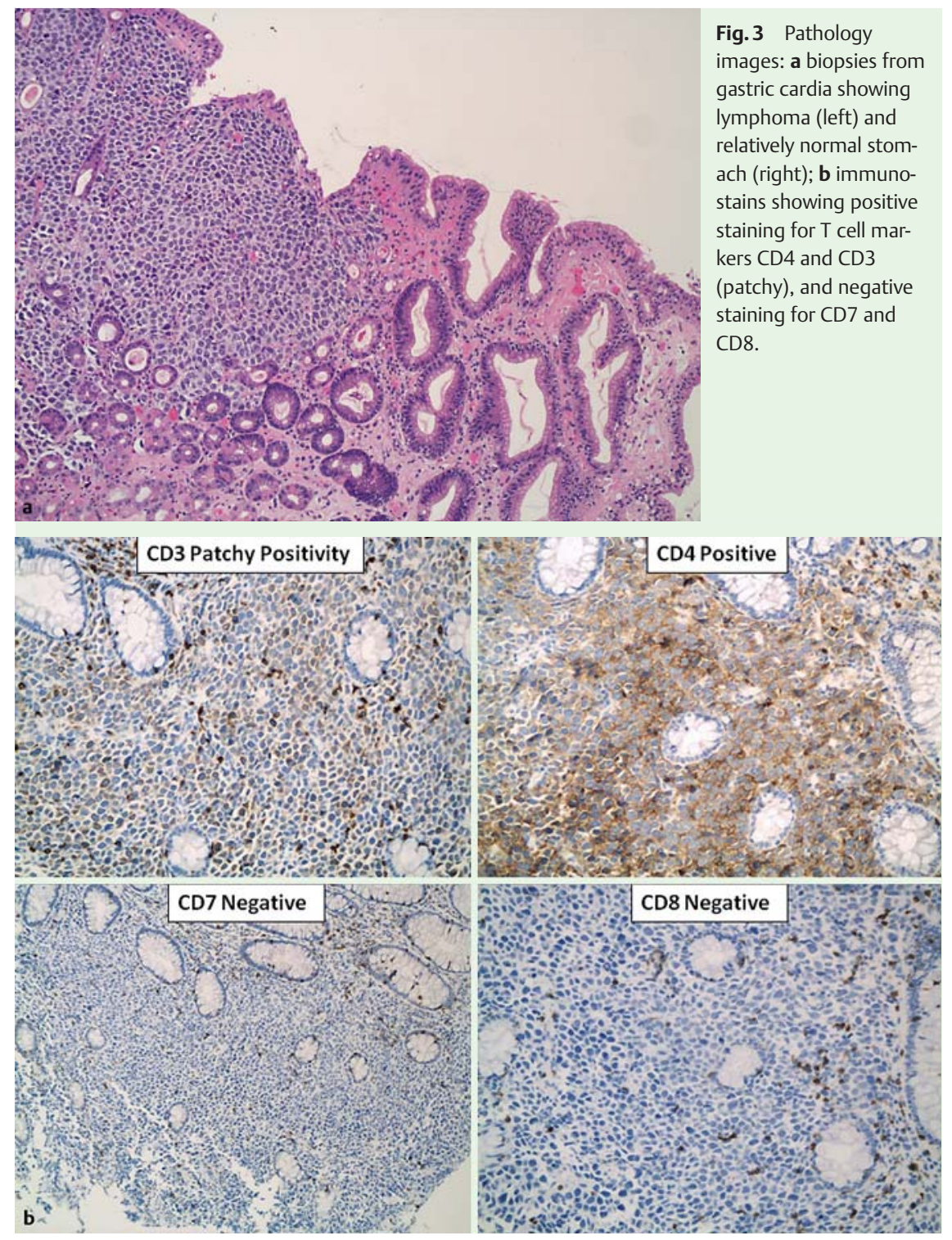

\section{References}

1 d'Amore F, Brincker H, Grønbaek K. Danish Lymphoma Study Group. et al. Non-Hodgkin's lymphoma of the gastrointestinal tract: a population-based analysis of incidence, geographic distribution, clinicopathologic presentation features, and prognosis. J Clin Oncol 1994; 12: 1673-1684

2 Koch P, del Valle F, Berdel WE et al. Primary gastrointestinal non-Hodgkin's lymphoma: I. Anatomic and histologic distribution, clinical features, and survival data of 371 patients registered in the German Multicenter Study GIT NHL 01/92. J Clin Oncol 2001; 19: 3861-3873

3 Biggar RJ, Engels EA, Frisch $M$ et al. Risk of T-cell lymphomas in persons with AIDS. J Acquir Immune Defic Syndr 2001; 26: $371-376$

4 Zhu $\mathrm{Q}, X u B, X u K$ et al. Primary non-Hodgkin's lymphoma in the esophagus. J Dig Dis 2008; 9: 241-244

\section{Bibliography}

DOI http://dx.doi.org/

10.1055/s-0032-1325856

Endoscopy 2013; 45: E31-E32

(c) Georg Thieme Verlag KG

Stuttgart · New York

ISSN 0013-726X

\section{Corresponding author \\ N. Thosani, MD, MHA}

Division of Gastroenterology, Hepatology and Nutrition

Department of Internal Medicine

6431 Fannin, MSB 4.234

Houston

Texas 77030

USA

Fax: +1-713-500-6699

Nirav.c.thosani@uth.tmc.edu 